\title{
Economic inequality in eye care utilization and its determinants: a Blinder-Oaxaca decomposition
}

\author{
Mohammad Hassan Emamian', Hojjat Zeraati ${ }^{2}$, Reza Majdzadeh ${ }^{2,3}$, Mohammad Shariati ${ }^{4}$, Hassan Hashemi ${ }^{5,6}$, \\ Akbar Fotouhi ${ }^{2, *}$
}

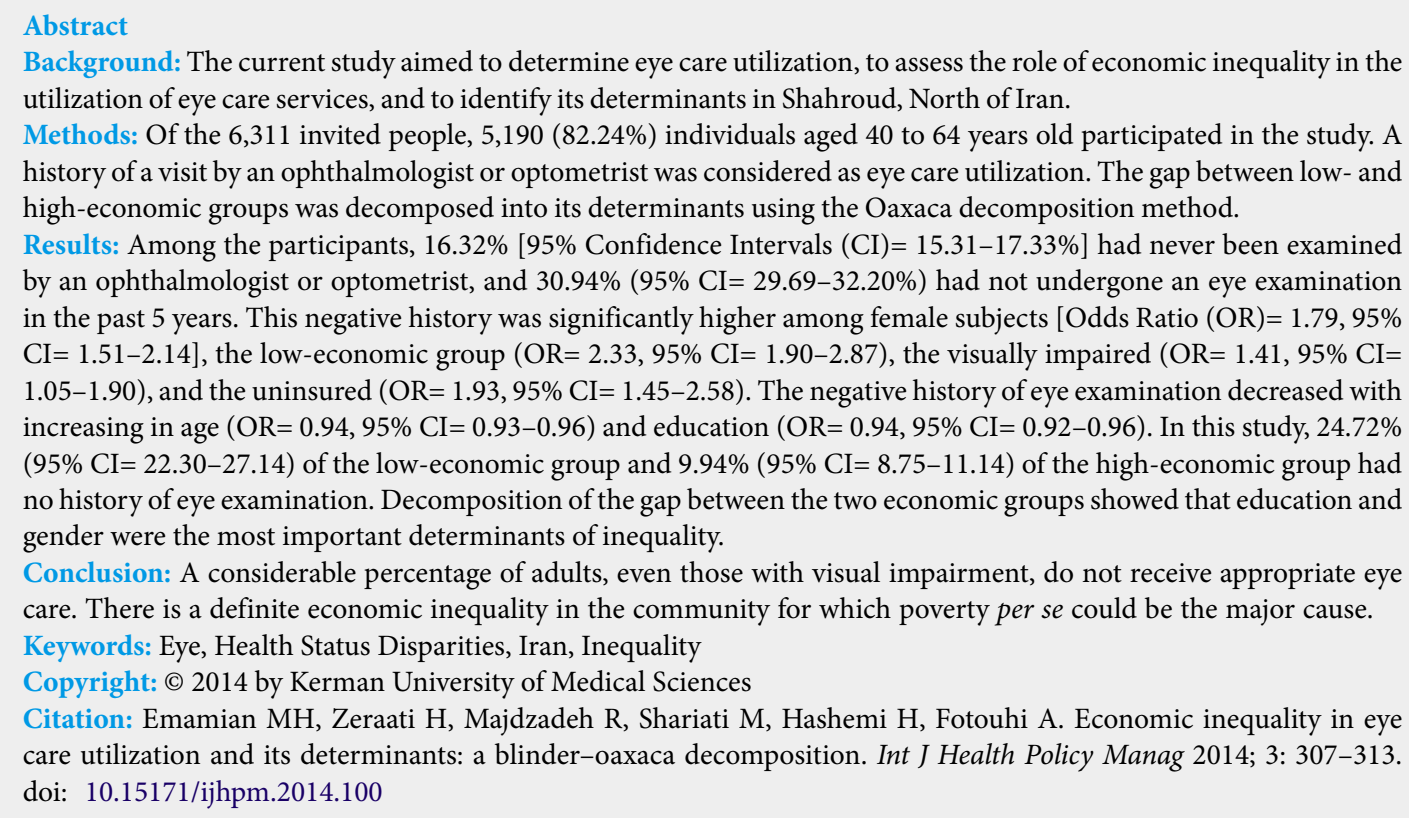

Background: The current study aimed to determine eye care utilization, to assess the role of economic inequality in the utilization of eye care services, and to identify its determinants in Shahroud, North of Iran.

Methods: Of the 6,311 invited people, 5,190 (82.24\%) individuals aged 40 to 64 years old participated in the study. A history of a visit by an ophthalmologist or optometrist was considered as eye care utilization. The gap between low- and high-economic groups was decomposed into its determinants using the Oaxaca decomposition method.

Results: Among the participants, 16.32\% [95\% Confidence Intervals $(\mathrm{CI})=15.31-17.33 \%]$ had never been examined by an ophthalmologist or optometrist, and 30.94\% (95\% CI=29.69-32.20\%) had not undergone an eye examination in the past 5 years. This negative history was significantly higher among female subjects [Odds Ratio (OR) $=1.79,95 \%$ $\mathrm{CI}=1.51-2.14]$, the low-economic group $(\mathrm{OR}=2.33,95 \% \mathrm{CI}=1.90-2.87)$, the visually impaired $(\mathrm{OR}=1.41,95 \% \mathrm{CI}=$ $1.05-1.90)$, and the uninsured $(\mathrm{OR}=1.93,95 \% \mathrm{CI}=1.45-2.58)$. The negative history of eye examination decreased with increasing in age $(\mathrm{OR}=0.94,95 \% \mathrm{CI}=0.93-0.96)$ and education $(\mathrm{OR}=0.94,95 \% \mathrm{CI}=0.92-0.96)$. In this study, $24.72 \%$ (95\% CI $=22.30-27.14)$ of the low-economic group and $9.94 \%$ (95\% CI= 8.75-11.14) of the high-economic group had no history of eye examination. Decomposition of the gap between the two economic groups showed that education and gender were the most important determinants of inequality.

Conclusion: A considerable percentage of adults, even those with visual impairment, do not receive appropriate eye care. There is a definite economic inequality in the community for which poverty per se could be the major cause. Keywords: Eye, Health Status Disparities, Iran, Inequality Copyright: @ 2014 by Kerman University of Medical Sciences

Citation: Emamian MH, Zeraati H, Majdzadeh R, Shariati M, Hashemi H, Fotouhi A. Economic inequality in eye care utilization and its determinants: a blinder-oaxaca decomposition. Int J Health Policy Manag 2014; 3: 307-313. doi: $10.15171 /$ ijhpm.2014.100

Article History:

Received: 1 June 2014 Accepted: 11 October 2014 ePublished: 13 October 2014

\section{*Correspondence to: Akbar Fotouhi}

Email: afotouhi@tums.ac.ir

\section{Key Messages}

Implications for policy makers

- A considerable percentage of adults have never used eye care services; education level, gender and economic status are important determinants of this gap.

- Oaxaca-Blinder is a good method for the decomposition of inequality to its determinants.

Implications for public

Any effort to enhance community education, reduce illiteracy and considering female gender in screening and healthcare programs, can reduce inequality in eye care utilization.

\section{Introduction}

In the 2020 global initiative for the elimination of avoidable blindness, increasing public awareness and encouraging the use of eye healthcare services are important strategies to integrate comprehensive eye health services (1). Several studies conducted worldwide have assessed the utilization of eye care services and factors affecting it (2-12). Adults should undergo a comprehensive eye examination every one or two years (13). However, studies in developing countries indicate that a considerable percentage of the population never avail of any eye care services $(3-5,10,11)$

The main goals of healthcare systems around the globe are to increase the general health status and to reduce inequalities in healthcare. The impact of economic inequality on health has been reported in several studies, which have carefully evaluated the ways in which income inequality adversely affects health (14). Income and health are causally related in two definite ways: through a direct effect on the individual's basic needs for survival and through indirect effects on social participation and opportunities for better control of life (15). Although economic inequality influences the health of both the poor and rich populations, the relationship between income inequality and health is not linear. Those in the lower $30 \%$ of earners would benefit the most from reduction in the 
gap between rich and poor (16).

Global research indicates that the majority of the visually impaired individuals live in developing countries. In particular, blindness due to cataract is most often observed in poor countries (1). Several studies on inequality have indicated that blindness is more prevalent in poor communities (17-19); gender disparity in eye diseases and access to eye care services has also been reported (20-22). Although reports of disparity in the frequency of utilization of eye care services (23-25) are available, we found no report on the role of economic inequality in utilization of eye care services.

The goals of vision 2020 will undoubtedly be made easier by understanding the extent of this disparity and its determinants. In this report, we have described our findings regarding the utilization of eye care services in an Iranian population by using data from the first phase of the Shahroud eye cohort study, which is a population-based study. We have also measured the economic inequality in the use of eye care services and decomposed it to its determinants.

\section{Methods \\ Study population}

The Shahroud eye cohort study was conducted in 2009 in Shahroud, in Northern Iran, with 5,190 respondents aged 40-64 years of age. Detailed descriptions of the method used in this study were published earlier (26) and are summarized here. Using stratified cluster sampling, 300 clusters were randomly selected from 9 strata in Shahroud where each healthcare center was considered one stratum. Clusters were selected proportional to the size of each stratum. At least 20 people aged between 40 and 64 years were selected for participating in the study in each cluster. After explaining the objectives of the study, they were invited to have a full eye examination. Of the 6,311 invitees, $82.24 \%$ participated in the study.

Shahroud, where most of the population is of average socioeconomic status, represents a typical Iranian urban population. The literacy rate in the population over six years $(87.80 \%)$ is slightly higher than the national average (84.75\%). Healthcare services are provided directly by Shahroud University of Medical Sciences (SHMU) similar to the case in centers in other provinces. Most specialty treatments including services for eye diseases are offered at city hospitals and private clinics. However, similar to other parts of Iran, optometric services for adults are not integrated with primary healthcare services.

\section{Measurements}

All the participants had completed vision tests, including uncorrected and best-corrected visual acuity measurements, auto-refraction, subjective and objective refraction tests, lensometry, contrast sensitivity, perimetry, intraocular pressure measurements, and complete ophthalmic examinations using slit-lamp biomicroscopy. Demographics, medical history, and other information were collected via a questionnaire.

Eye care service utilization was considered as the self-reported use of any kind of eye care service (examination) by an ophthalmologist or optometrist. Considering the prevalence of eye examinations reported by other studies performed in Iran, we included two questions regarding utilization of eye care services: The independent variables were age, gender, education, economic status, presenting vision (more than 0.30 LogMAR compare to 0.30 or less), and insurance status. Participants with any type of insurance at the time of the study were considered as having valid insurance. Age, gender, and education were considered as predisposing factors according to a theoretical framework of relevant variables (Andersen's model) (27), while presenting vision was the need factor or illness level in this model. We divided the study population into three economic tertiles, as described below. Considering the high-economic group as the reference, this trichotomous variable was used to investigate the role of economic status on utilization of eye care services. Economic and insurance statuses were considered as enabling factors in Anderson's model.

The gap in utilization of eye care services was defined as the difference between the prevalence of utilization of eye care services among individuals in the first (high-economic group) and third (low-economic group) tertiles. Other variables that had a significant effect on utilization of eye care services included age, gender, education, presenting vision and insurance status. These were investigated in decomposition analysis as independent variables.

\section{Statistical analyses}

The effects of socio-economic factors on the dependent variables were investigated using logistic regression analysis in four models. In the first model we included only need variable as independent variable, while in the second and third models we added predisposing and enabling variables. In the last model, all independent variables included as a full model. In order to maximize the precision of this analysis, we entered age and education as continuous variables in the regression models.

To assess the economic disparity in this study population, individuals were classified into different economic groups. Because the income itself was unclear and there is no acceptable standard method for dividing a population into different economic groups. We therefore implemented the method described by O'Donnell et al. (28). First, we applied Principal Component Analysis (PCA) to 11 sets of home assets, as reported by the study participants. In this analysis, the highest Eigenvalues were associated with the possession of a private bath within the residence, a microwave oven, and a dishwasher. These three factors were responsible for $51.77 \%$ of the variance observed. We then constructed the asset index (weighted by the first PCA factor) and then divided the variable into three tertiles. The first group was considered as the higheconomic group and the third as the low-economic group.

The gap between the high- and low-economic in terms of utilization of eye care services was deconstructed into its determinants by using the Blinder-Oaxaca decomposition method $(29,30)$.

This method is based on two regression models, fitted separately for the two population groups (in this study, highand low-economic groups) (31). 
1) $Y_{H}=\beta X_{H}+\varepsilon_{H}$

2) $Y_{L}=\beta X_{L}+\varepsilon_{L}$

In above formulas $Y$ is the outcome variable, $\beta$ is the coefficient including the intercept, $X$ is the explanatory variable, and $\varepsilon$ is the error.

The gap between the two groups is:

3) $\bar{y}_{H}-\bar{y}_{L}=\left(\bar{x}_{H}-\bar{x}_{L}\right) \beta_{H}+\bar{x}_{L}\left(\beta_{H}-\beta_{L}\right)$

and

4) $\bar{y}_{L}-\bar{y}_{H}=\left(\bar{x}_{H}-\bar{x}_{L}\right) \beta_{L}+\bar{x}_{H}\left(\beta_{H}-\beta_{L}\right)$

The first part of the right hand of the above equations is the observable difference in the variables in the two groups (the endowment or explained component) and the second part is differences in the variable coefficients in the two groups (the coefficient or unexplained component).

This technique divides the gap between the mean of an outcome variable into two components. The "explained or endowment" component arises because of differences in the groups' characteristics, such as differences in education or insurance status, and an "unexplained or coefficient" component is attributed to the different effects of these characteristics in either group (28).

To perform the decomposition, we constructed a logistic regression model with independent variables in each economic group to determine the regression coefficients $(\beta)$ as the main effect and its interaction with the other independent variables. By using the method described by Jann (32), we ran the Oaxaca command in version 10 of the Stata software (Stata Corporation, College Station, Texas) program. $P<0.05$ was considered as significant in all statistical tests. A design effect of cluster sampling was considered when calculating the $95 \%$ Confidence Intervals (CI).

Results

Out of a total of 5,190 participants in the study, we obtained data for utilization of eye care services from 5,184 people. Among these individuals, $16.32 \%$ (95\% CI=15.31-17.33) had never been examined by an ophthalmologist or optometrist, while $30.94 \%$ (95\% CI=29.69-32.20) had not presented to an ophthalmologist or optometrist in the last five years.

As seen in Table 1, women, and individuals who were young, less educated, from low-economic group, uninsured, or with presenting vision worse than 0.30 LogMAR (worse than 20/40) were less likely than their counterparts to have visited an eye care service provider. In every group aside from those aged 60-64 years, the proportion of people who were never examined decreased with age among both men and women. Of the 344 people who had a presenting vision worse than 20/40 in the better eye, $23.84 \%$ had never visited any eye care service provider (Table 1), despite a need for eye care. In the same group, $45.64 \%$ had not visited an eye care service provider in the last five years despite the need for annual examinations.

The multiple logistic regression models revealed a significant association between a negative history of eye care and age, gender, education, economic status, presenting vision, and insurance status. As shown in Table 2, economic status was significantly associated with the receipt of eye care services. The reverse correlation of age and education with the outcome

Table 1. Eye care services utilization according to different independent variables, Shahroud, Iran, 2009

\begin{tabular}{|c|c|c|c|c|}
\hline Independent variables & & Number & No eye care visit $\%$ (95\% Cl) & $\begin{array}{l}\text { No eye care visit in the last } 5 \\
\text { years } \%(95 \% \mathrm{Cl})\end{array}$ \\
\hline \multirow{14}{*}{ Predisposing variables } & Gender & & & \\
\hline & Men & 2210 & $10.63(9.12-12.14)$ & $28.82(26.68-30.98)$ \\
\hline & Women & 2974 & $20.50(18.84-22.24)$ & $32.52(30.43-34.60)$ \\
\hline & Age & & & \\
\hline & $40-44$ & 960 & $23.22(20.66-25.79)$ & $38.64(35.58-41.71)$ \\
\hline & $45-49$ & 1386 & $17.46(15.27-19.65)$ & $31.29(28.39-34.20)$ \\
\hline & $50-54$ & 1284 & $14.10(12.18-16.02)$ & $26.93(24.46-29.39)$ \\
\hline & $55-59$ & 954 & 11.74 (9.55-13.93) & $25.58(22.68-28.48)$ \\
\hline & 60-64 & 600 & $14.66(11.87-17.45)$ & $34.94(31.14-38.73)$ \\
\hline & Education & & & \\
\hline & Illiterate & 426 & $30.99(26.53-35.44)$ & $43.56(38.47-48.65)$ \\
\hline & Primary school & 2593 & $19.13(17.38-20.88)$ & $33.53(31.21-35.84)$ \\
\hline & Guidance school & 481 & $12.27(8.98-15.56)$ & $28.27(23.90-32.64)$ \\
\hline & College & 541 & $6.10(4.00-8.20)$ & $19.41(15.71-23.11)$ \\
\hline \multirow{7}{*}{ Enabling variables } & Economic status & & & \\
\hline & High & $2376^{b}$ & $9.93(8.58-11.28)$ & 24.87 (22.78-26.97) \\
\hline & Middle & 1433 & $18.42(16.45-20.39)$ & $33.50(30.99-36.00)$ \\
\hline & Low & 1373 & $25.20(22.54-27.86)$ & 38.53 (35.39-41.67) \\
\hline & Insurance status & & & \\
\hline & Insured & $4790^{c}$ & $15.17(13.89-16.47)$ & $29.71(27.97-31.45)$ \\
\hline & Not insured & 282 & $31.91(26.12-37.71)$ & $46.81(40.35-53.27)$ \\
\hline \multirow{3}{*}{ Need variable } & Presenting vision & & & \\
\hline & $<0.30$ LogMar & $4838^{b}$ & $15.79(14.48-17.11)$ & $29.83(28.09-31.56)$ \\
\hline & $\geq 0.30$ LogMar & 344 & $23.84(19.23-28.44)$ & $45.64(40.37-50.91)$ \\
\hline
\end{tabular}

$\mathrm{Cl}=$ Confidence Interval; $\mathrm{a}=$ No eye examination by optometrist or ophthalmologist; $\mathrm{b}=$ Data were available for 5,182 participants; $\mathrm{c}=\mathrm{Data}$ were available for 5,072 participants 
variable was statistically significant.

Comparison of different regression models reveals the effects of predisposing and enabling factors on outcome variable. Even in the third model the need variable has not a significant effect on negative history of eye care after adjusting for enabling factor $(P=0.060)$.

Table 3 shows that $24.72 \%(95 \% \mathrm{CI}=22.30-27.14)$ of the loweconomic group $(n=1,373)$ and $9.94 \%(95 \% C I=8.75-11.14)$ of the high-economic group $(n=2,376)$ had never undergone an eye examination by an ophthalmologist or an optometrist. This accounts for a $14.77 \%$ gap in favor of the high-economic group. Only $6.04 \%$ of this gap can be attributed to differences in the studied variables between the two groups (explained component).

In other words, if those in the low-economic group were similar to those in the high-economic group in terms of the variables mentioned above, the difference in the prevalence of a negative history of visits for eye care would have been $8.73 \%$ rather than $14.77 \%$. The most important variables in the explained component appeared to be education $(-5.27 \%)$ and age $(1.29 \%)$, although no causal relationship can be proven in a cross-sectional study such as this.

The remaining gap (i.e. $8.73 \%$ of the difference in the prevalence of a negative history of visits for eye care and

Table 2. Multivariate odds ratio $(95 \% \mathrm{Cl})$ for never visiting an eye care provider in different logistic regression models, Shahroud, Iran, 2009

\begin{tabular}{|c|c|c|c|c|c|}
\hline \multirow{2}{*}{\multicolumn{2}{|c|}{ Independent variables }} & \multicolumn{4}{|c|}{ Adjusted odds ratio $(95 \% \mathrm{Cl})$} \\
\hline & & Model 1 $1^{a}$ & Model $2^{\mathrm{b}}$ & Model $3^{c}$ & Model $4^{d}$ \\
\hline \multirow{5}{*}{$\begin{array}{l}\text { Predisposing } \\
\text { variables }\end{array}$} & Age (year) & & $0.95(0.94-0.96)$ & & $0.94(0.93-0.96)$ \\
\hline & Education (year) & & $0.91(0.89-0.93)$ & & $0.94(0.92-0.96)$ \\
\hline & Gender & & & & \\
\hline & Men & & 1 & & 1 \\
\hline & Women & & $1.80(1.51-2.13)$ & & $1.79(1.51-2.14)$ \\
\hline \multirow{7}{*}{ Enabling variables } & Economic Status & & & & \\
\hline & High & & & 1 & 1 \\
\hline & Moderate & & & $1.97(1.62-2.39)$ & $1.81(1.48-2.21)$ \\
\hline & Low & & & $2.74(2.24-3.36$ & $2.33(1.90-2.87)$ \\
\hline & Insurance Status & & & & \\
\hline & Insured & & & 1 & 1 \\
\hline & Not Insured & & & $2.14(1.62-2.83)$ & $1.93(1.45-2.58)$ \\
\hline \multirow{3}{*}{ Need variable } & Presenting vision & & & & \\
\hline & $\leq 0.30$ LogMAR & 1 & 1 & 1 & 1 \\
\hline & $>0.30$ LogMAR & $1.67(1.28-2.17)$ & $1.59(1.21-2.11)$ & $1.31(0.99-1.73)$ & $1.41(1.05-1.90)$ \\
\hline
\end{tabular}

$\mathrm{Cl}=$ Confidence Interval; $\mathrm{a}=$ Include only need variable as an Univariate model; $\mathrm{b}=$ Include need and predisposing variables; $\mathrm{c}=$ Include need and enabling variables $\mathrm{d}=$ Include need, predisposing and enabling variables.

Table 3. Decomposition of the difference in eye care utilization between two economic groups, men and women aged 40 to 64 years, Shahroud, Iran, 2009

\begin{tabular}{|c|c|c|c|c|c|}
\hline \multicolumn{2}{|l|}{ No eye care visit } & \multirow{2}{*}{$\begin{array}{c}\text { Prediction (\%) } \\
9.94\end{array}$} & \multicolumn{2}{|c|}{$95 \% \mathrm{Cl}$} & $\mathbf{P}$ \\
\hline Prevalence in High group & & & 8.75 & 11.14 & $<0.001$ \\
\hline Prevalence in Low group & & 24.72 & 22.30 & 27.14 & $<0.001$ \\
\hline Differences (Total Gap) & & -14.77 & -17.47 & -12.07 & $<0.001$ \\
\hline \multicolumn{6}{|c|}{ Due to endowments (explained) ${ }^{a}$} \\
\hline \multicolumn{6}{|c|}{ Predisposing variables } \\
\hline & Age & 1.29 & 0.80 & 1.78 & $<0.001$ \\
\hline & Education & -5.27 & -6.38 & -4.15 & $<0.001$ \\
\hline & Gender & -1.09 & -1.47 & -0.70 & $<0.001$ \\
\hline Enabling variable & Insurance & -0.63 & -0.98 & -0.29 & $<0.001$ \\
\hline \multirow[t]{2}{*}{ Need variable } & Presenting vision & -0.34 & -0.65 & -0.03 & 0.032 \\
\hline & Sub Total Gap (explained part) & -6.04 & -11.03 & -6.43 & $<0.001$ \\
\hline \multicolumn{6}{|c|}{ Due to coefficients (unexplained) ${ }^{b}$} \\
\hline \multicolumn{6}{|c|}{ Predisposing variables } \\
\hline & Age & -15.42 & -33.99 & 3.14 & 0.103 \\
\hline & Education & 2.71 & -0.25 & 5.68 & 0.073 \\
\hline & Gender & -4.14 & -5.94 & -2.35 & $<0.001$ \\
\hline Enabling variable & Insurance & -3.93 & -13.95 & 6.09 & 0.442 \\
\hline \multirow[t]{3}{*}{ Need variable } & Presenting vision & 0.43 & -0.06 & 0.93 & 0.085 \\
\hline & Constant & 11.63 & -10.09 & 33.35 & 0.294 \\
\hline & Sub Total Gap (unexplained part) & -8.73 & -11.03 & -6.43 & $<0.001$ \\
\hline
\end{tabular}

$\mathrm{Cl}=$ Confidence Interval; $\mathrm{a}=$ Part of gap that related to differences in independent variables between two groups; $\mathrm{b}=$ Part of gap that related to differences of coefficients $(\beta)$ of regression models in two groups. 
$59.11 \%$ of the total gap) reflected between-group differences in the effects of the variables studied, as well as other factors that were not included in this study (unexplained component). In this part only gender was found to significantly contribute to the gap between the two economic groups (Table 3 ).

\section{Discussion}

We found that $16.32 \%$ of participants had never used ophthalmologic or optometric services and that $30.94 \%$ of these individuals had not done so over the past five years. These rates are lower than those reported by Fotouhi et al. (5). The obvious explanation is the difference in the age distributions of each population.

Our results showed that negative history for eye care utilization decreased significantly with increasing age and education, having valid insurance and higher economic status. This is in agreement with reports from other countries $(2,3,5,7,9,11,12,23-25,33)$. Nevertheless, in contrast to other studies, $(5,7,9,24,25)$ gender inequality was more serious in our study, where women were seen to be more deprived of eye care services than men. This difference was significant in simple as well as multiple logistic regression models. In a study of individuals aged higher than 18 years in Tehran (5), men showed a higher probability of not having used eye care services. This was determined using a multiple logistic regression model adjusted for age and education [Odds Ratio (OR), 1.30; 95\% CI=1.11-1.51]. However, the opposite was true in our study. A similar comparison revealed a greater number of women who had never used eye care services $(\mathrm{OR}, 1.79 ; 95 \% \mathrm{CI}=1.51-2.14)$. When service utilization over the past five years was considered, we found no inter-gender difference $(\mathrm{OR}, 1.02 ; 95 \% \mathrm{CI}=0.91-1.16)$. This discrepancy likely stems from differences in terms of age distribution, education level, employment, and women's social life. The inter-gender difference observed in our study is similar to that reported by Nirmalan et al. (11) in rural India, where men were more likely to receive eye care services in hospitals. However, the authors reported no significant gender difference in the utilization of eye care services.

Our results regarding utilization of eye care services were much better than those reported by Nirmalan et al. (11) They found that $65 \%$ had never received eye care. This group included individuals with presenting vision of $0.6-1.3$ $\log$ MAR (3/60 to 6/24).

Among this population of Shahroud inhabitants, $94.40 \%$ were insured. Although some eye care services were not covered, a complete failure to utilize eye care services was more prevalent among the uninsured (OR, 1.93; 95\% CI=1.452.58). Similarly, other studies have shown that utilization of eye care services is less common among the uninsured individuals $(2,6,7,9)$.

The highest ORs for simple as well multiple regression analysis were observed while comparing low- vs. high-economic groups. This indicates the important role of economic status in utilization of eye care services. In other words, there is a gap between the utilizing of eye care services to low- vs. high-economic groups. As revealed in Table 3, the difference between high- and low-economic groups was $14.77 \%$. Only
$6.04 \%$ of this difference ( $40.89 \%$ of the gap) was owing to differences in education, age, presenting vision, insurance status, and gender. The remaining gap (unexplained) comprised additional factors that prevent low-economic group from obtaining eye care. The most significant determinant of the explained component was education status.

The lower level of education in the low-economic group was the main factor responsible for the explained component (Table 3). The effect of age is significant in favor of the loweconomic group, mainly because older individuals were also more likely to be uneducated: the mean age among loweconomic group was 52.19 years; among high-economic group, the mean age was 49.83 years $(P<0.001)$.

Table 2 shows that women were more likely to have gone their entire lives without visiting an eye care service provider (OR, 1.79; 95\% CI= 1.51-2.14). Furthermore, $51.94 \%$ of the high-economic group interviewed was women. Alternatively, women made up $65.99 \%$ of the low-economic group. These findings justify the significant role of gender in both explained and unexplained components of the Oaxaca decomposition. It must be noted that a greater part of the gap (59.11\%) was related to the unexplained component. This may be attributed to factors that correlate with poverty but were not included in the decomposition. The findings presented above show that striving to equalize the utilization of men and women to eye care services will be more effective in battling economic inequality than would efforts to equalize level of education among different economic groups of the population.

Numerous studies have used regression models to investigate the role of income in utilization of eye care services (23-25). To the best of our knowledge, no study has been done regarding the economic gap in eye care utilization and its determinant. Researchers have studied the role of income in the overall utilization of health-related services. For example, Xie (34) decomposed the concentration index and found a pro-rich inequality in the utilization of healthcare services, where people with a higher income were healthier and used more healthcare services. The authors concluded that the role of income as a determinant of inequality in healthcare was increasing. Similarly, van Doorslaer et al. (35) found a prorich inequity in the utilization of specialty services in Europe. The strengths of this study include a large sample size, a high response rate, good design, and the degree of quality control during its execution. Most studies on visual health have been done in older adults, while this study focused on the middle-aged population. However, we had no national index with which to divide the population into different economic groups, as was the case in many other developing countries. Therefore, we created the index using home assets. This index, if calculated correctly, is considered to be a robust tool for grouping a population (36). Another limitation of our study was the inability to separate the services offered by ophthalmologists from those provided by optometrists, as well as inpatient care from outpatient care. We also have no data on the attitudes of the population towards eye care and knowledge about eye disease. We suggest that these factors need to be taken into consideration in the next phases of the study. Our data may also have some degree of recall bias. 
Finally, it must be emphasized that the correlations identified in this cross-sectional study do not necessarily reflect causational relationships.

Here, we used regression analysis to investigate the patterns of utilization of eye care services and the associated determinants among a middle-aged urban population in Iran. We also deconstructed the gap between low- and higheconomic groups by using a rather unconventional method. The results of this analysis showed that efforts to reduce age and education disparities were responsible for only $40.89 \%$ of this gap. In fact, for removing the remaining gap it is necessary to consider gender equality and other undetermined factors such as poverty. This issue is an important reason for using decomposition methods for investigating health inequality. Therefore, in public health point of view, conventional regression models are not sufficient to identify the role of each factor contributing to a given disparity.

\section{Conclusion}

A considerable percentage of adults never use eye care services; this percentage varies considerably between lowand high-economic groups. Although education level and gender are important determinants of this gap, it is mainly attributable to economic status. More attention to women's health, literacy and poverty alleviation, both in the region and at national level should be considered. Such a situation may exist in other developing countries that could be of interest to policy-makers. Further studies should focus on the effect of economic status on people's access to services as well as service-seeking behavior.

\section{Acknowledgments}

This project was supported by Noor Ophthalmology Research Center and Shahroud University of Medical Sciences (SHMU). The present study was supported by Tehran University of Medical Sciences (TUMS) as a PhD thesis.

\section{Ethical issues}

All the participants signed the informed consent form after the study was explained thoroughly. The Ethics Committee of Shahroud University of Medical Sciences (SHMU) approved the study, which was conducted in accord with the tenets of the Declaration of Helsinki.

\section{Competing interests}

The authors declare that they have no competing interests.

\section{Authors' contributions}

MHE drafted the manuscript as his $\mathrm{PhD}$ Thesis and contributed to preparation of the study protocol and conceptualized and conducted all statistical analyses and is the primary author of the article. $\mathrm{HZ}, \mathrm{RM}$, and MS contributed to the conceptualization of the paper and the statistical analyses and critically revised the manuscript and approved it. $\mathrm{HH}$ and $\mathrm{AF}$ conceived and designed the study and contributed to preparation of the study protocol and were involved in data collection supervision and contributed to the conceptualization of the paper and the statistical analyses and critically revised the manuscript and approved it.

\section{Authors' affiliations}

${ }^{1}$ Center for Health Related Social and Behavioral Sciences Research, Shahroud University of Medical Sciences, Shahroud, Iran. ${ }^{2}$ Department of Epidemiology and Biostatistics, School of Public Health, Tehran University of Medical Sciences, Tehran, Iran. ${ }^{3}$ Knowledge Utilization Research Center (KURC),
Tehran University of Medical Sciences, Tehran, Iran. ${ }^{4}$ Department of Community Medicine, School of Medicine, Tehran University of Medical Sciences, Tehran, Iran. ${ }^{5}$ Noor Ophthalmology Research Center, Noor Eye Hospital, Tehran, Iran. ${ }^{6}$ Farabi Eye Hospital, School of Medicine, Tehran University of Medical Sciences, Tehran, Iran.

\section{References}

1. World Health Organization (WHO). Global Initiative for the Elimination of Avoidable Blindness: action plan 2006-2011. Geneva: WHO; 2007.

2. Centers for Disease Control and Prevention (CDC). Eye-care utilization among women aged $>$ or $=40$ years with eye diseases - 19 states, 2006-2008. MMWR Morb Mortal Wkly Rep 2010; 59: 588-91.

3. Dandona R, Dandona L, Naduvilath TJ, McCarty CA, Rao GN. Utilisation of eyecare services in an urban population in southern India: the Andhra Pradesh eye disease study. $\mathrm{Br} J$ Ophthalmol 2000; 84: 22-7. doi: 10.1136/bjo.84.1.22

4. du Toit R, Ramke J, Naduvilath T, Brian G. Awareness and use of eye care services in Fiji. Ophthalmic Epidemiol 2006; 13: 30920. doi: 10.1080/09286580600826629

5. Fotouhi A, Hashemi H, Mohammad K. Eye care utilization patterns in Tehran population: a population based crosssectional study. BMC Ophthalmol 2006; 6: 4.

6. Keeffe JE, Weih LM, McCarty CA, Taylor HR. Utilisation of eye care services by urban and rural Australians. Br J Ophthalmol 2002; 86: 24-7.

7. Lee DJ, Lam BL, Arora S, Arheart KL, McCollister KE, Zheng $\mathrm{DD}$, et al. Reported eye care utilization and health insurance status among US adults. Arch Ophthalmol 2009; 127: 303-10.

8. McGwin G, Khoury R, Cross J, Owsley C. Vision impairment and eye care utilization among Americans 50 and older. Curr Eye Res 2010; 35: 451-8. doi: 10.1186/1471-2415-6-4

9. Morales LS, Varma R, Paz SH, Lai MY, Mazhar K, Andersen RM, et al. Self-reported use of eye care among Latinos: the Los Angeles Latino Eye Study. Ophthalmology 2010; 117: 207-15. doi: 10.1016/j.ophtha.2009.07.015

10. Ndegwa LK, Karimurio J, Okelo RO, Adala HS. Barriers to utilisation of eye care services in Kibera slums of Nairobi. East Afr Med J 2005; 82: 506-8. doi: 10.4314/eamj.v82i10.9347

11. Nirmalan PK, Katz J, Robin AL, Krishnadas R, Ramakrishnan R, Thulasiraj RD, et al. Utilisation of eye care services in rural south India: the Aravind Comprehensive Eye Survey. Br J Ophthalmol 2004; 88: 1237-41. doi: 10.1016/s0161-6420(04)00535-4

12. Orr P, Barrón Y, Schein OD, Rubin GS, West SK. Eye care utilization by older Americans: the SEE Project. Salisbury Eye Evaluation. Ophthalmology 1999; 106: 904-9. doi: 10.1016/ s0161-6420(99)00508-4

13. Rowe $\mathrm{S}$, MacLean $\mathrm{CH}$, Shekelle PG. Preventing visual loss from chronic eye disease in primary care: scientific review. JAMA 2004; 291: 1487-95. doi: 10.1001/jama.291.12.1487

14. Leigh A, Jencks C, Smeeding TM. Health and Economic Inequality. In: Salverda W, Nolan B, Smeeding TM, editors. Oxford Handbook of Economic Inequality. Oxford: Oxford University Press; 2009. p. 385-405.

15. Marmot $M$. The influence of income on health: views of an epidemiologist. Health Aff (Millwood) 2002; 21: 31-46. doi: 10.1377/hIthaff.21.2.31

16. Dowd JB, Albright J, Raghunathan TE, Schoeni RF, Leclere F, Kaplan GA. Deeper and wider: income and mortality in the USA over three decades. Int J Epidemiol 2011; 40: 183-8. doi: 10.1093/ije/dyq189

17. Gilbert CE, Shah SP, Jadoon MZ, Bourne R, Dineen B, Khan $\mathrm{MA}$, et al. Poverty and blindness in Pakistan: results from the Pakistan national blindness and visual impairment survey. BMJ 
2008; 336: 29-32. doi: 10.1136/bmj.39395.500046.ae

18. Ho VH, Schwab IR. Social economic development in the prevention of global blindness. Br J Ophthalmol 2001; 85: 653-7.

19. Khanna R, Raman U, Rao GN. Blindness and poverty in India: the way forward. Clin Exp Optom 2007; 90: 406-14. doi: 10.1111/j.1444-0938.2007.00199.x

20. Harris B, Sampson G. Gender differences in the utilisation of optometric services in Victoria. Clin Exp Optom 2005; 88: 10912. doi: 10.1111/j.1444-0938.2005.tb06676.x

21. Jansen $E$, Baltussen RM, van Doorslaer $E$, Ngirwamungu $E$, Nguyen MP, Kilima PM. An Eye for Inequality: How Trachoma Relates to Poverty in Tanzania and Vietnam. Ophthalmic Epidemiol 2007; 14: 278-87. doi: 10.1080/09286580701299403

22. Kuper H, Polack S, Eusebio C, Mathenge W, Wadud Z, Foster A. A Case-Control Study to Assess the Relationship between Poverty and Visual Impairment from Cataract in Kenya, the Philippines, and Bangladesh. PLoS Med 2008; 5: 1716-28. doi: 10.1371/journal.pmed.0050244

23. Chou CF, Barker LE, Crews JE, Primo SA, Zhang X, Elliott AF, et al. Disparities in Eye Care Utilization Among the United States Adults With Visual Impairment: Findings From the Behavioral Risk Factor Surveillance System 2006-2009. Am J Ophthalmol 2012; 154: S45-52. doi: 10.1016/j.ajo.2011.09.025

24. Jin YP, Trope GE. Eye care utilization in Canada: disparity in the publicly funded health care system. Can J Ophthalmol 2011; 46: 133-38. doi: 10.3129/i10-120

25. Vela C, Samson E, Zunzunegui MV, Haddad S, Aubin MJ, Freeman EE. Eye care utilization by older adults in low, middle, and high income countries. BMC Ophthalmol 2012; 12 : 5 doi: 10.1186/1471-2415-12-5

26. Fotouhi $A$, Hashemi $H$, Shariati M, Emamian MH, Yazdani $K$, Jafarzadehpur E, et al. Cohort Profile: Shahroud Eye Cohort Study. Int J Epidemiol 2013; 42: 1300-8. doi: 10.1093/ije/dys161
27. Andersen R, Newman JF. Societal and individual determinants of medical care utilization in the United States. Milbank Q 1973; 51: 95-124. doi: 10.1111/j.1468-0009.2005.00428.x

28. O'Donnell $O$, van Doorslaer E, Wagstaff $A$, Lindelow $M$. Analyzing Health Equity Using Household Survey Data A Guide to Techniques and Their Implementation. Washington, DC: The World Bank; 2008.

29. Blinder AS. Wage Discrimination: Reduced Forms and Structural Estimates. J Hum Resour 1973; 8: 436-55. doi: 10.2307/144855

30. Oaxaca R. Male-Female Wage Differentials in Urban Labor Market. Int Econ Rev 1973; 14: 693-709. doi: 10.2307/2525981

31. Jimenez-Rubio D, Hernandez-Quevedo $C$. Inequalities in the use of health services between immigrants and the native population in Spain: what is driving the differences? Eur J Health Econ 201; 12: 17-28. doi: 10.1007/s10198-010-0220-z

32. Jann B. A Stata implementation of the Blinder-Oaxaca decomposition. Stata J 2008; 8: 453-79.

33. Schaumberg DA, Christen WG, Glynn RJ, Buring JE. Demographic predictors of eye care utilization among women. Med Care 2000; 38: 638-46. doi: 10.1097/00005650-20000600000005

34. Xie E. Income-Related Inequalities of Health and Health Care Utilization. Front Econ China 2011; 6: 131-56. doi: 10.1007/ s11459-011-0125-5

35. van Doorslaer E, Koolman X, Jones AM. Explaining incomerelated inequalities in doctor utilisation in Europe. Health Econ 2004; 13: 629-47. doi: 10.1002/hec.919

36. Wagstaff A, Waters H. How Were the Reaching the Poor Studies Done. In: Gwatkin DR WA, Yasbeck AS, editors. Reaching the Poor with Health, Nutrition, and Population Services: What Works, What Doesn't, and Why. Washington, DC: The World Bank; 2005. p. 27-46. 